\title{
Static structural CAE analysis of symmetrical 65Si7 leaf springs in automotive vehicles
}

\author{
Vinkel Kumar Arora ${ }^{a^{*}}$, Gian Bhushan ${ }^{\mathrm{b}}$ and M.L Aggarwale
}

${ }^{a}$ Department of Mechanical Engineering, ITM University, Sector-23A, Guragaon-122017, Haryana, India

${ }^{b}$ Department of Mechanical Engineering, National Institute of Technology, Kurukshetra-136019, Haryana, India

${ }^{c}$ Department of Mechanical Engineering, YMCA University of Science \&Technology, Faridabad-121006, Haryana, India

ART ICLE INFO ABSTRACT

Article history:

Received March 6, 2014

Accepted 23 August 2014

Available online

15 October 2014

Keywords:

Static Structural analysis

Leaf springs

Computer Aided Engineering

(CAE)

$65 \mathrm{Si} 7$

Load rate

\begin{abstract}
Leaf springs in vehicles are used to absorb, store and release energy. During this cycle stresses induced in the springs must not exceed design stress, in order to avoid settling or premature failure. Number of experiments are done in order to determine the stresses, load rate and deflection, which involves lot of time and cost. Today, the technologies in leaf springs are changing gradually; therefore new tools are required to keep aligned with worldwide technological requirements. The work presented in this paper provides a CAE solution to static analysis of $65 \mathrm{Si} 7$ leaf springs used in light commercial vehicles (LCV's). A practical model of leaf spring used in LCV has been taken into consideration for this study. It has been experimentally tested for deflection, stress and load rate on a full scale leaf spring testing machine. A static structural CAE analysis of leaf spring has been done under similar loading condition. The CAD model of the leaf spring has been prepared in solid works and analyzed using ANSYS. Using CAE tools, ideal type of contact and meshing elements have been proposed to achieve results closer to the experimental results. The analytical method for static analysis of the leaf springs has also been described. CAE results have been compared with experimental and analytical results for validation.
\end{abstract}

\section{Introduction}

The leaf springs are one of the oldest suspension components and they are still frequently used, especially in commercial vehicles. Leaf springs are also known as laminated springs or semi-elliptical spring, as it takes the form of a slender arc shaped length of spring steel of rectangular cross section. In heavy vehicles, leaves are stacked one upon the other to ensure rigidity and strength. It provides dampness and springing function. It can be attached directly to the frame at the both ends or attached

* Corresponding author. Tel.: +91-9654984179

E-mail addresses: vinkelarora@gmail.com (V. K. Arora) 
directly to one end usually at the front with the other end attached through a shackle, a short swinging arm. The shackle takes up the tendency of the leaf spring to elongate when it gets compressed and by which the spring becomes softer.

A full scale testing machine has to be used for determination of the stress and deformation in the leaf springs, which is time consuming. An analytical method for obtaining stress and deformation is also available but it also involves lot of time. With a slight change in grade of the leaf, the entire process needs to be repeated in experimental and analytical approach which affects the product development. Today, the technologies in leaf springs are changing gradually; therefore new tools are required to keep aligned with worldwide technological requirements. CAE tools are widely used in the automotive industries. In fact, their use has enabled the spring makers to reduce product development cost and time while improving durability and comfort. The predictive capability of CAE tools has progressed to the point where much of the design verification is now done using computer simulation rather than physical prototype testing. CAE dependability is based upon all proper assumptions as inputs and must identify critical inputs. Even though there have been many advances in CAE, and it is widely used in the engineering field, physical testing is still used as a final confirmation for subsystems due to the fact that CAE cannot predict all variables in complex assemblies, therefore the validation of CAE results is important.

Aggarwal et al. (2006 a) evaluated the axial fatigue strength of EN45A spring steel specimen experimentally as a function of shot peening in the conditions used. $\mathrm{S} / \mathrm{N}$ curves of the specimens were correlated with leaf springs curve in vehicles. Aggarwal et al. (2006 b) concluded that influence of high contact pressure and temperatures resulted in micro weld between the two leaf surfaces. The fatigue strength of the leaf springs was studied as a function of shot peening parameters. Chantranuwathana et al. (2009) simulated a leaf springs model. An experimental leaf springs model was verified by using a leaf springs test rig that could measure vertical static deflection of leaf springs under static loading condition. The results showed a non-linear relationship between the applied load and the leaf springs deflection for both directions of loading, in form of a hysteresis loop. Fuentes et al. (2008) studied the origin of premature failure analysis procedures, including examining the leaf spring history. The visual inspection of fractured specimens and simulation tests on real components were also performed. It was concluded that fracture occurred by a mechanism of mechanical fatigue initiated at the region of the central hole, which suffered the highest tensile stress levels. An initiated crack around the center hole region can then be propagated due to cyclic fatigue loads and the remaining service life of spring can be estimated using the fracture mechanics principals (Torabi and Aliha, 2013). Junior et al. (2010) suggested a thermal sprayed HVOF technology. This induced residual stress on the interface of the springs and improved fatigue life. Kumar and Vijayrangan (2007) described static and fatigue analysis of steel leaf springs and composite multi leaf springs made up of glass fibre reinforced polymer using life data analysis. The dimensions of an existing conventional steel leaf spring of a light commercial vehicle were taken and verified by design calculations. Static analysis of 2-D model of conventional leaf springs was also performed using ANSYS 7.1 and compared with experimental results. Patunkar et al. (2011) worked on non-linear force displacement of each leaf spring as well as the spring characteristics of a pack consist of two to four leaves using ANSYS. The results from ANSYS were compared with those from the test, which showed a fairly good agreement with each other. Arora et al. (2011) described the CAE solution for static analysis of the leaf springs and compared CAE results with experimental results by considering two loads only, the load rate was specified but not tested. In CAE analysis, the load was applied at the center and eyes and pins were the fixed supports. The center nut bolt was also not considered for CAE evaluation.

The objective of this work is to provide static structural CAE solution for symmetrical $65 \mathrm{Si} 7$ leaf springs used in a light commercial vehicle by taking into consideration the experimental testing. The paper has been divided into three parts. In part one, leaf springs have been experimentally tested on a 
full-scale leaf spring testing machine, to determine deflection, load rate and stresses under the defined load conditions. The load rate of the springs has been determined experimentally, by taking the mean values of loading and unloading of the leaf springs. An experimental load deflection curve has been drawn from results. In the second part, the CAD model of the leaf springs has been prepared in solid works and static analysis of the leaf springs has been carried out using ANSYS. The boundary and loading conditions have been defined by taking into consideration the experimental testing conditions. The deflection and stresses have been determined by using CAE approach under same load. A load- deflection curve has also been drawn from the results. In the third part, analytical approach as specified by SAE spring design manual has been used to determine the deflection and stresses under same load. The weight of the leaf springs assembly has also been determined using $\mathrm{CAE}$ and analytical approach. The results have been compared for validation and CAE solution has been proposed to industry as an alternate to experimental and analytical solution.

\section{Material}

The selection of the spring material is based upon the application and section required to attain required load rate. The basic requirements of a leaf spring steel is that the selected grade of steel must have sufficient hardenability for the size involved, to ensure a full martenstic structure throughout the entire leaf section. In general terms higher alloy content is mandatory to ensure adequate hardenability when the thick leaf sections are used. The material used for the experimental work is 65Si7.The chemical composition of the material is C- $0.53 \%$, Si- $0.20 \%$, Mn- $0.72 \%, \mathrm{~S}-0.007 \%$, P$0.019 \%$ and $\mathrm{Cr}-0.73 \%$.Steels of the same hardness in the tempered martensite condition have approximately the same tensile and ultimate strength. The ductility is inversely proportional to the hardness for the heat treated steel. The mechanical properties for leaf springs application are obtained within the range of BHN 380-432. The Mechanical properties and parameters of the $65 \mathrm{Si} 7$ are Young's Modulus, (E)- $200124 \mathrm{MPa}, \mathrm{BHN}-380-432$, Poisson's Ratio( $\mu$ )-0.266, Tensile Ultimate strength $\left(\mathrm{S}_{\mathrm{ut}}\right)-1272 \mathrm{MPa}$, Tensile Yield strength $\left(\mathrm{S}_{\mathrm{y}}\right)-1081.2 \mathrm{MPa}$, Elongation (min)-7\%, $\operatorname{Density}(\rho)-0.00000785 \mathrm{~kg} / \mathrm{mm}^{3}$. The material is heat-treated at $880^{\circ} \mathrm{C}$, and oil quench hardened and it is tempered at $410^{\circ} \mathrm{C}$, for 90 minutes to get tempered martensite structure.

\section{Leaf springs design parameters}

A leaf spring is considered as a beam of uniform strength composed of leaves of equal thickness where the fiber stress is same throughout the length of the beam. This approximation is justified for most of the springs within the accuracy necessary for layout work and with certain correction factors for estimate of required length, overhang, camber, width, thickness and number of leaves. The calculation of these parameters involves certain number of steps. The parameters are categorized as design parameters. The various parameters associated with the design of the leaf springs are shown in the Table 1.

Table 1. Design parameters of the leaf springs

\begin{tabular}{|c|c|c|c|c|c|c|c|c|c|c|c|}
\hline \multirow{2}{*}{$\begin{array}{l}\text { Span } \\
(\mathrm{mm})\end{array}$} & \multirow{2}{*}{$\begin{array}{l}\text { Load rate } \\
(\mathrm{N} / \mathrm{mm})\end{array}$} & \multicolumn{2}{|c|}{ Load(N) } & \multirow{2}{*}{$\begin{array}{c}\text { No } \\
\text { Load } \\
\text { Camber } \\
(\mathrm{mm})\end{array}$} & \multirow{2}{*}{$\begin{array}{l}\text { Seat } \\
\text { Length } \\
(\mathrm{mm})\end{array}$} & \multirow{2}{*}{$\begin{array}{c}\text { Total } \\
\text { number } \\
\text { of } \\
\text { leaves }\end{array}$} & \multirow{2}{*}{$\begin{array}{l}\text { No. of } \\
\text { full } \\
\text { length } \\
\text { leaves }\end{array}$} & \multirow{2}{*}{$\begin{array}{l}\text { Maximum } \\
\text { thickness of } \\
\text { the } \\
\text { individual } \\
\text { leaf * width } \\
(\mathrm{mm} * \mathrm{~mm})\end{array}$} & \multirow{2}{*}{$\begin{array}{c}\text { Ride } \\
\text { Clearance } \\
(\mathrm{mm})\end{array}$} & \multirow[b]{2}{*}{$\begin{array}{l}\text { Stiffening } \\
\text { factor }\end{array}$} & \multirow{2}{*}{$\begin{array}{c}\text { Master } \\
\text { leaf eye } \\
\text { type }\end{array}$} \\
\hline & & Design & Maximum & & & & & & & & \\
\hline $1150 \pm 3$ & $\begin{array}{c}159.11 \pm \\
7 \%\end{array}$ & 12959 & 28010 & $95 \pm 4$ & 100 & 12 & 2 & $8 * 70$ & 94.6 & 1.1 & $\begin{array}{l}\text { Upturned } \\
\text { Berlin } \\
\text { eye }\end{array}$ \\
\hline
\end{tabular}


The drawing of the conventional 65Si7 leaf springs which, constitute of total 12 tapered ends leaves of $8 \mathrm{~mm}$ thickness and $70 \mathrm{~mm}$ width, with two full length leaves is shown in the figure 1.

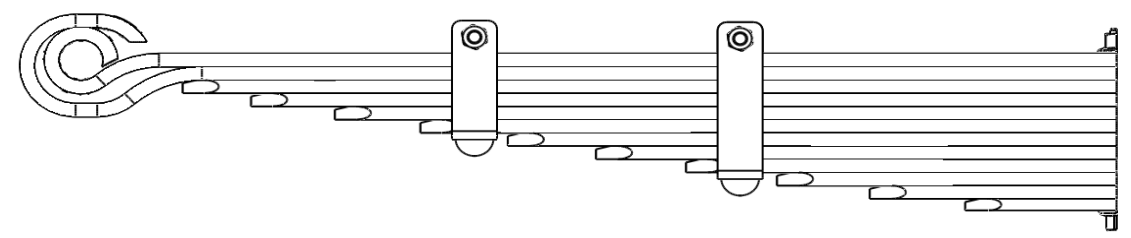

\section{Experimental Setup}

Fig. 1. Drawing of the leaf springs

The symmetrical 65Si7 leaf springs assembly consists of two full length leaves and ten graduated leaves, four rebound clips of mild steel, four shim pipes with four nut and bolts, four rivets, center nut and bolt and bush of bronze.

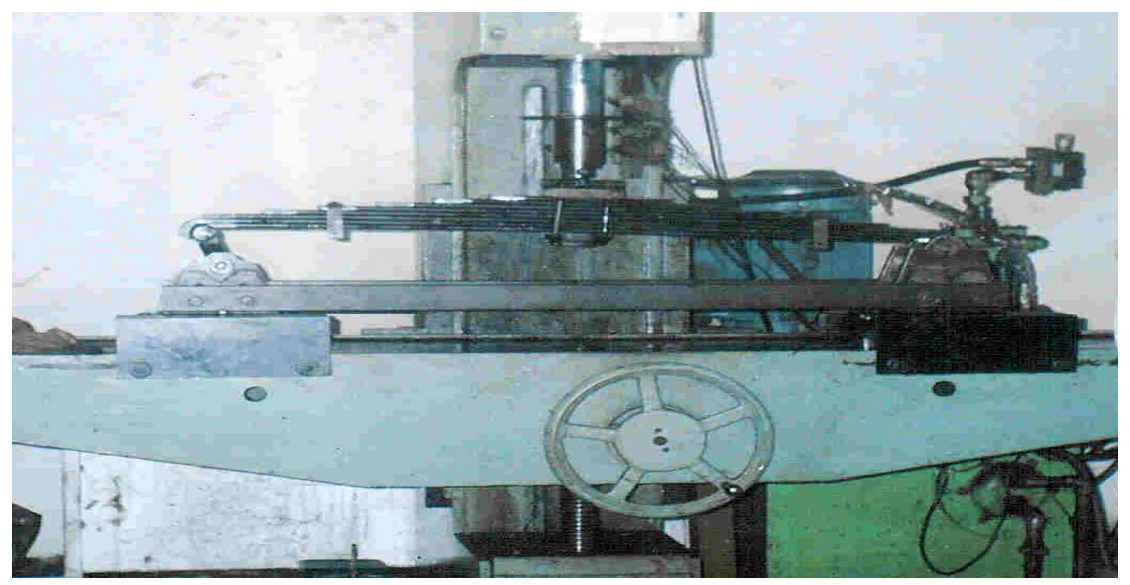

Fig. 2. Full scale leaf springs testing machine

Fig. 2 shows an experimental setup which consists of a full scale testing machine for leaf spring, jigs and fixture. The full scale testing of leaf springs was carried out in a electro-hydraulic static component testing system. The laminated leaf springs were placed in a fixture simulating the conditions of a vehicle. The setup consists of a hydraulic power pack to give a hydraulic pressure of 20.6 MPa with a flow rate of 210 liters per minute $(1 \mathrm{pm})$, which is sent to a hydraulic actuator to operate at a frequency of $0.3 \mathrm{~Hz}$ with the displacement specified by the alternating load. This involves applying the axial load on the leaf springs and measure the deflection and bending stress. The conventional leaf spring is tested under static load condition by using hydraulic static load ram for load application. Mounting of the leaf spring is done by keeping it in inverted manner on the test bed. Two eye ends are held in the clamping devices and load is applied from the top, at the center of leaf springs. To measure the load dial indicator is used which is located beside the full scale testing machine and deflection is measured by strain gauges located at the clamping of the test rig. The springs are loaded from unladen load (i.e. $7.6 \mathrm{KN}$ ) to maximum load (i.e. $28 \mathrm{KN}$ ). The vertical deflection of the springs at the unladen load, design load, flat load, rubber touching load and metal to metal contact or maximum load is recorded respectively, as per the standard operating procedure prescribed by society of automotive engineers spring design manual (1990).

\subsection{Test for load rate determination}

The spring ends are mounted in carriages with rollers free to move in the direction of the datum line. The spring is supported by its ends and the load applied downward to the shortest 
leaf. The loading block through which the load is applied is coaxial over the center bolt/cup center with the legs of the $\mathrm{V}$ resting on the spring. The assembled spring is then deflected thrice by an amount according to the design specification. After this operation the spring is compressed from no load to maximum load and released to its no load position. The loads corresponding to 25 percent of the maximum spring deflection below and above the rated load position during the compression and release of the spring are noted. The spring is loaded in compression and release loads. The load rate is the slope of the average of the compression and release loads at the two deflections recorded. Table 2 shows that during the loading of leaf springs (compression load) the load is on the higher end as compared to the unloading (release load) for same deflection.

Table 2. Experimental results of loading and unloading of the leaf springs for load rate test

\begin{tabular}{|c|c|c|c|c|c|}
\hline $\begin{array}{c}\text { Deflection } \\
(\mathrm{mm})\end{array}$ & $\begin{array}{l}\text { Loading } \\
(\mathrm{kg})\end{array}$ & $\begin{array}{c}\text { Unloading } \\
(\mathrm{kg})\end{array}$ & $\begin{array}{c}\text { Mean } \\
(\mathrm{kg})\end{array}$ & $\begin{array}{l}\mathrm{L} / \text { Rate } \\
\mathrm{kg} / \mathrm{mm}\end{array}$ & $\begin{array}{c}\text { Av. L/Rate } \\
\mathrm{kg} / \mathrm{mm}\end{array}$ \\
\hline 0 & 0 & 0 & 0 & 0 & \multirow{18}{*}{$16.26 \mathrm{~kg} / / \mathrm{mm}$} \\
\hline 10 & 160 & 80 & 120 & 16 & \\
\hline 20 & 340 & 220 & 280 & 16 & \\
\hline 30 & 520 & 360 & 440 & 17 & \\
\hline 40 & 700 & 520 & 610 & 16.5 & \\
\hline 50 & 870 & 680 & 775 & 15.5 & \\
\hline 60 & 1040 & 820 & 930 & 17 & \\
\hline 70 & 1200 & 1000 & 1100 & 16 & \\
\hline 80 & 1370 & 1150 & 1260 & 17 & \\
\hline 90 & 1540 & 1320 & 1430 & 17 & \\
\hline 100 & 1720 & 1480 & 1600 & 17.5 & \\
\hline 110 & 1900 & 1650 & 1775 & 18.5 & \\
\hline 120 & 2100 & 1820 & 1960 & 18 & \\
\hline 130 & 2280 & 2000 & 2140 & 17.5 & \\
\hline 140 & 2480 & 2150 & 2315 & 18.5 & \\
\hline 150 & 2660 & 2340 & 2500 & 21.5 & \\
\hline 160 & 2890 & 2540 & 2715 & 17 & \\
\hline 170 & 3060 & 2710 & 2885 & 17 & \\
\hline
\end{tabular}

\subsection{Test for deflection and stress determination}

The leaf springs is tested on a full scale testing machine under the unladen, rated, flat, rubber touching load and metal to metal load and the corresponding deflection and stress values observed are shown in the Table 3 . This table depicts the observed values of deflection and stress (measured by strain gauges applied on the leaf spring assembly) corresponding to the loads applied on the shorter leaf by a static hydraulic ram. The experiments are performed twice and the mean of two values is considered for the study.

Table 3. Experimental results for load, deflection and bending stresses

\begin{tabular}{lllll}
\hline $\begin{array}{l}\text { Spring } \\
\text { No }\end{array}$ & Load type & Load $(\mathrm{N})$ & Deflection $(\mathrm{mm})$ & Bending Stress(MPa) \\
\hline 1 & Unladen load & 7661 & 46.9 & 262 \\
2 & Design/Rated load & 12959 & 81.44 & 446 \\
3 & Flat load & 15754 & 99 & 540 \\
4 & Rubber touching load & 21645.7 & 136. & 743 \\
5 & Metal to Metal contact & 28010 & 176 & 941 \\
\hline
\end{tabular}




\section{Computer aided engineering analysis}

The CAE analysis of the leaf spring begins with the CAD modelling and assembly of the individual leaves from the standard drawing of the leaf spring. The leaf spring assembly is imported to an analysis software ANSYS. The various contacts are set and entire model is discretized into small elements. The boundary conditions are applied by taking into consideration the experimental testing conditions and the post processor gives the solution. The various steps involved in CAE analysis is as follow:

\subsection{CAD modelling}

CAD modelling of any project is one of the most time consuming process. One cannot shoot directly from the form sketches to finite element model. CAD Modelling is the base of any project. A finite element software will consider shapes, whatever is made in CAD model. The CAD modelling of the complete multi leaf springs structure is performed by using solid works software. The CAD model of leaf springs consists of total 34 different parts which are assembled together in assembly design to make a complete multi leaf springs assembly. Out of all 34 parts, some parts are similar in shape and size. This CAD model of multi leaf springs used for analysis is shown in Fig. 3.
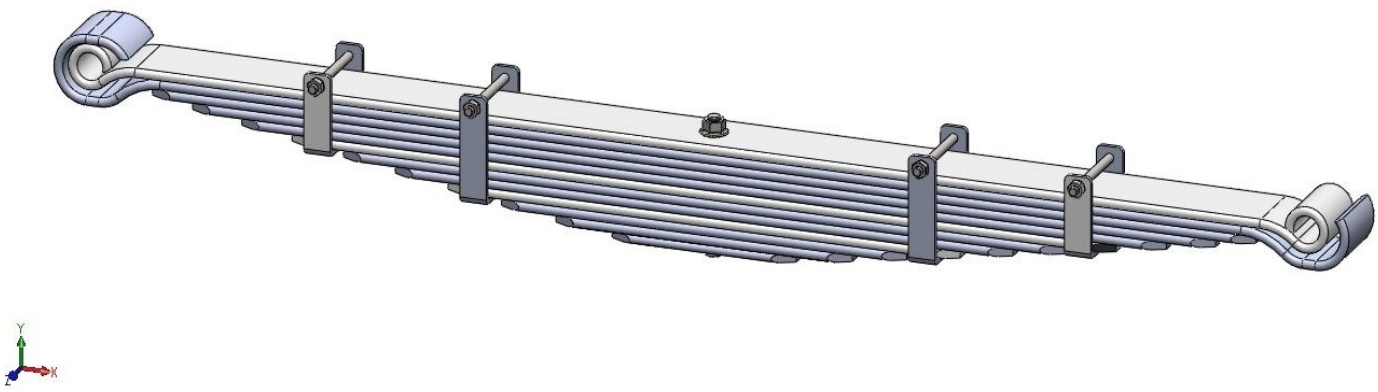

Fig. 3. CAD model of the leaf springs in soliworks

\subsection{Analysis using ANSYS}

The CAD model of leaf springs has been imported into ANSYS as shown below in Fig. 4. All the boundary conditions and material properties has specified as per the standards used in the practical application. The material used for the leaf springs for analysis is $65 \mathrm{Si} 7$, which is having isotropic behaviour.

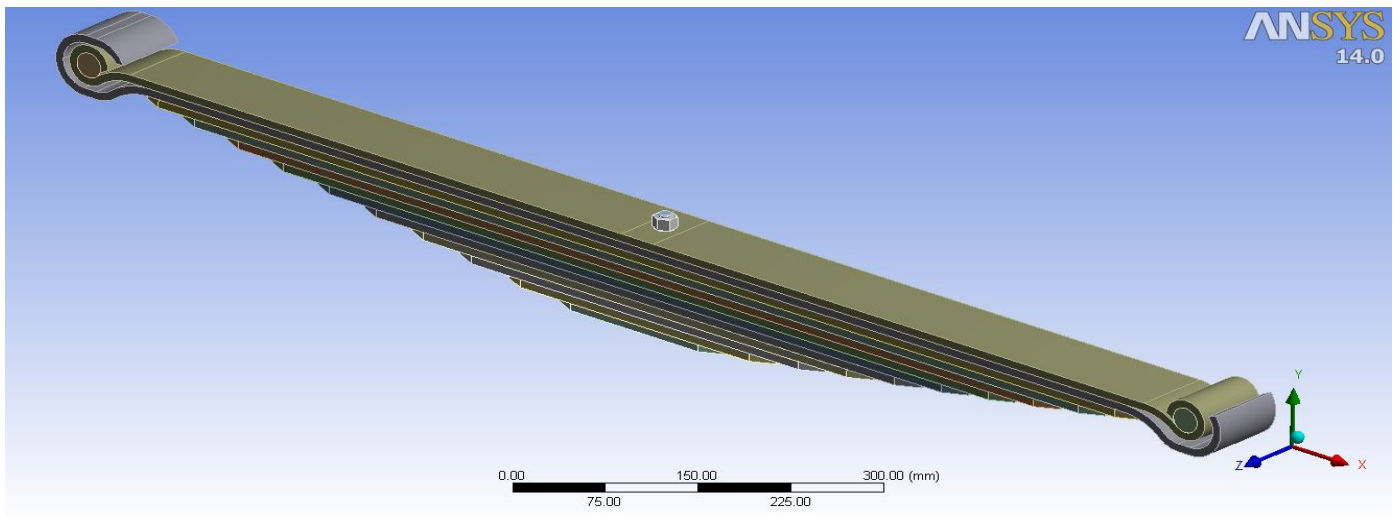

Fig. 4. CAD Model imported in ANSYS 
The procedure for performing analysis in ANSYS involves:

\subsubsection{Setting up the contact reign}

The contact conditions are formed where bodies meet. The differences in the contact settings determine how the contacting bodies can move relative to one another. This is the most common setting and has the most impact on what other settings are available. When an assembly is imported from a CAD system, contact between various parts is automatically detected. The automatically detected contact regions are bonded, which means they will behave like a welded joints with zero degree of freedom. Most of these types apply to contact regions made up of faces only. In this assembly the No separation contact is used for the analysis. It only applies to regions of faces. Separation of faces in contact is not allowed, but small amounts of frictionless sliding can occur along contact faces. In general CONTA174 and TARGE170 are used. CONTA174 is used for contact and sliding between 3D target surfaces (TARGE170), which is defined by this element. The element is applicable to 3D structural analysis. TARGE170 is used to represent various 3D target surfaces for the associated contact elements. The contact elements themselves overlay the solid, shell, or line elements describing the boundary of a deformable body and are potentially in contact with the target surface, which is defined by TARGE170. This target surface is discretized by a set of target segment elements (TARGE170) and is paired with its associated contact surface via a shared real constant set. The various contact region sets up in the leaf springs are shown in the Fig. 5.

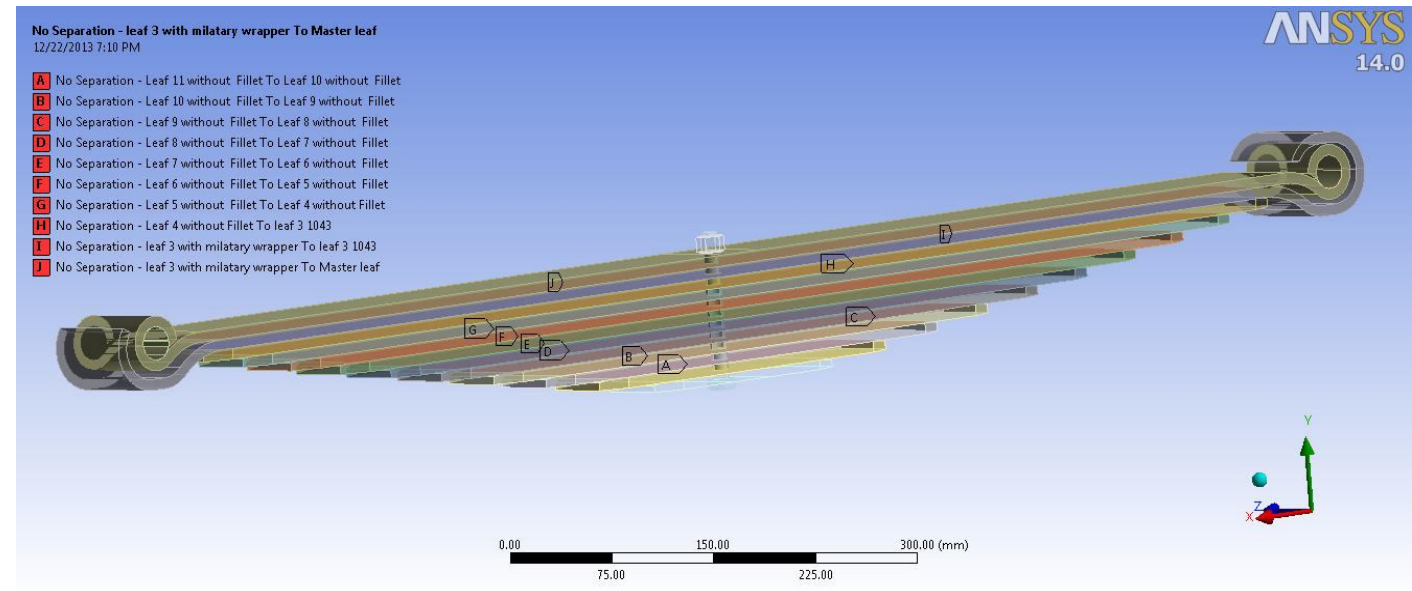

Fig. 5. No Separation contact between the leaves

\subsubsection{Meshing}

Meshing is the process in which geometry is spatially discretized into elements and nodes. This mesh along with material properties is used to mathematically represent the stiffness and weight distribution of structure. The default element size is determined based on a number of factors including the overall model size, the proximity of other topologies, body curvature, and the complexity of the feature. If necessary, the fineness of the mesh is adjusted up to four times (eight times for an assembly) to achieve a successful mesh. In this assembly SOLID187 element, which is a standard mechanical element for solids, is used for the results. SOLID187 element is a higher order 3D, 10-node element. SOLID187 has quadratic displacement behaviour and is well suited to modelling irregular meshes. The element is defined by 10 nodes having three degrees of freedom at each node: translations in the nodal $\mathrm{x}, \mathrm{y}$, and $\mathrm{z}$ directions. The number of SOLID 187 elements is 6964 and number of nodes generated are 16943. The meshed model of the leaf spring assembly is shown in Fig. 6. 


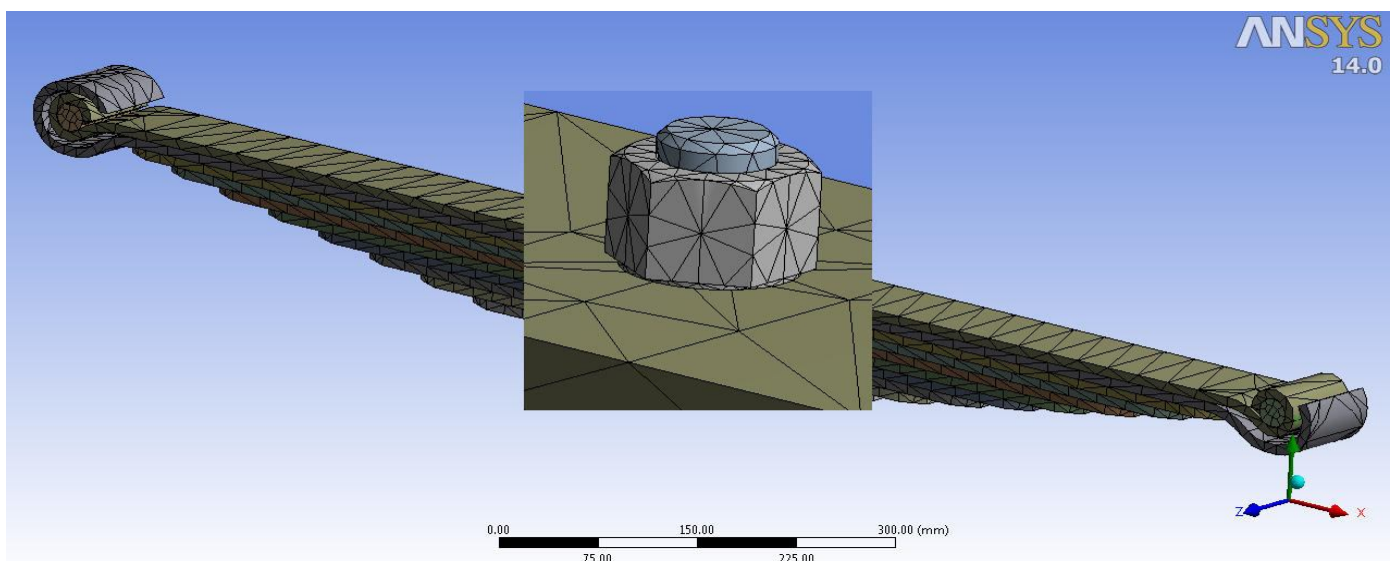

Fig. 6. Meshed model of the leaf springs

\subsubsection{Static Analysis module in ANSYS}

A static structural analysis determines the displacements, stresses, strains, and forces in structures or components caused by loads that do not induce significant inertia and damping effects. Steady loading and response conditions are assumed; that is, the loads and the structure's response are assumed to vary slowly with respect to time. Static structure analysis takes into consideration some parameters, like material properties, loading conditions, support conditions and contacts which are to be specified as the input to the pre-processing of the analysis.

\subsubsection{Applying boundary conditions}

The boundary conditions are applied by taking into consideration the experimental loading conditions. The springs have been modelled in flat condition and the loading is done to achieve the initial condition. The total load is divided on the two eyes of the master leaf and pins. The fixed support constitutes the seat length (on master leaf and last $\left(12^{\text {th }}\right.$ leaf)) and the centre bolt. The CAE boundary conditions are shown in the Fig. 7.

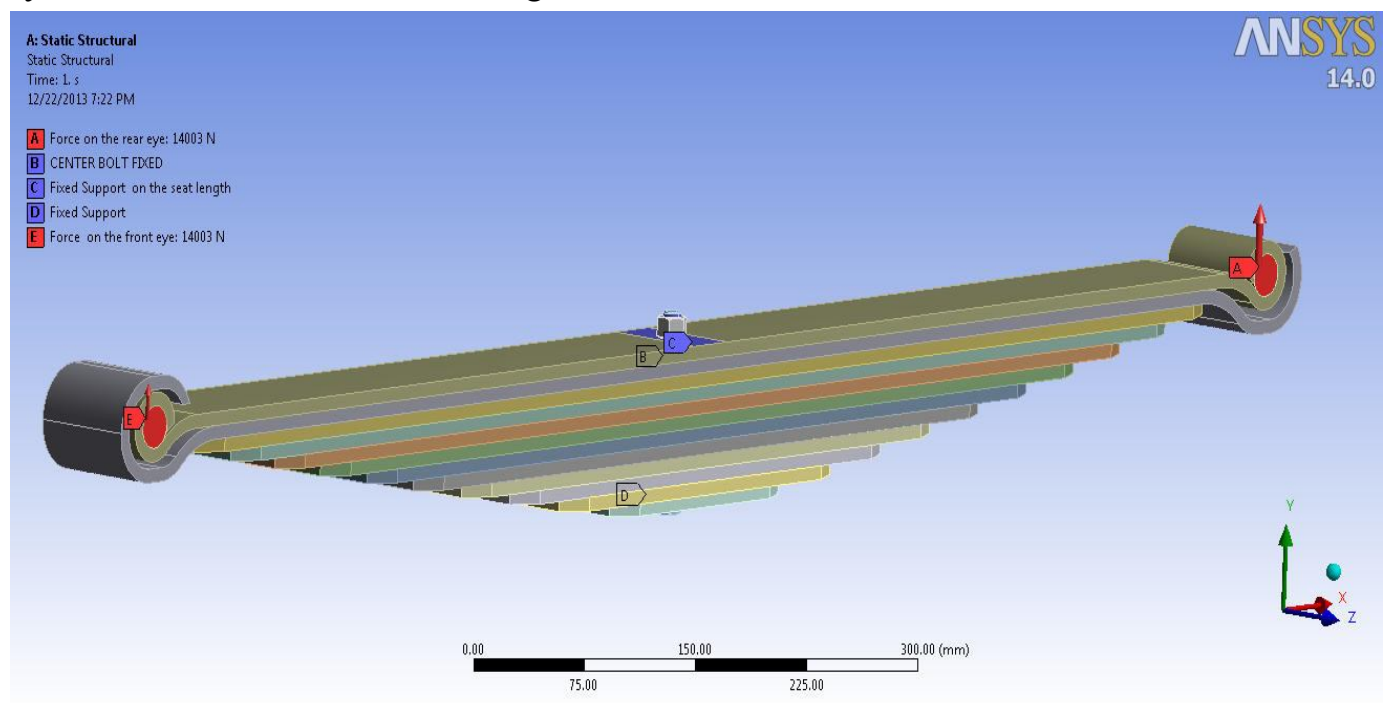

Fig. 7. Boundary conditions for CAE analysis 


\section{Solution}

The static environment is set and boundary conditions are applied, the post processor gives the solution. Fig. 8 shows that deformation contours under the metal to metal contact load $(28010 \mathrm{~N})$ applied on the leaf springs eyes. It is observed that maximum deformation occurs at the eye end in the leaf spring assembly and minimum deformation occurs in the seat length region of the leaf springs. The figure 9 shows the stress contour under the metal to metal load. The maximum stress is observed at the seat length region while minimum stress is observed in the eyes of the leaf springs. The maximum value of the stress induced is $989 \mathrm{MPa}$ which is well below the yield stress of the material.

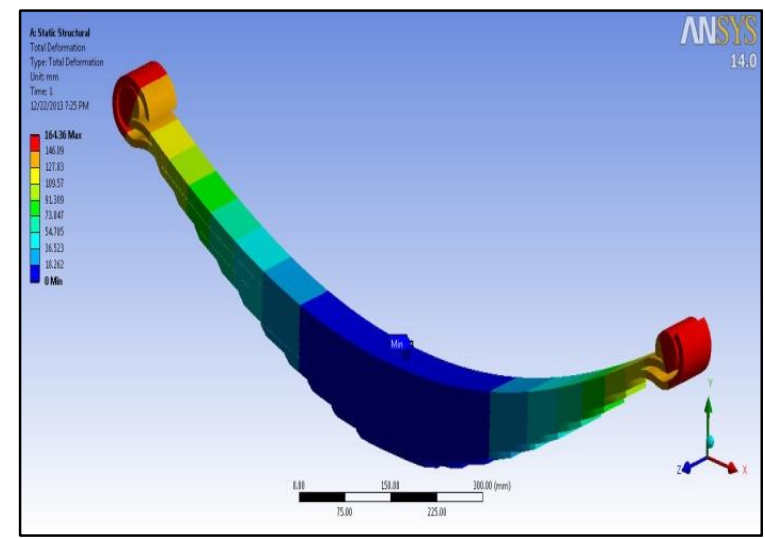

Fig. 8. Total deformation at metal to metal load

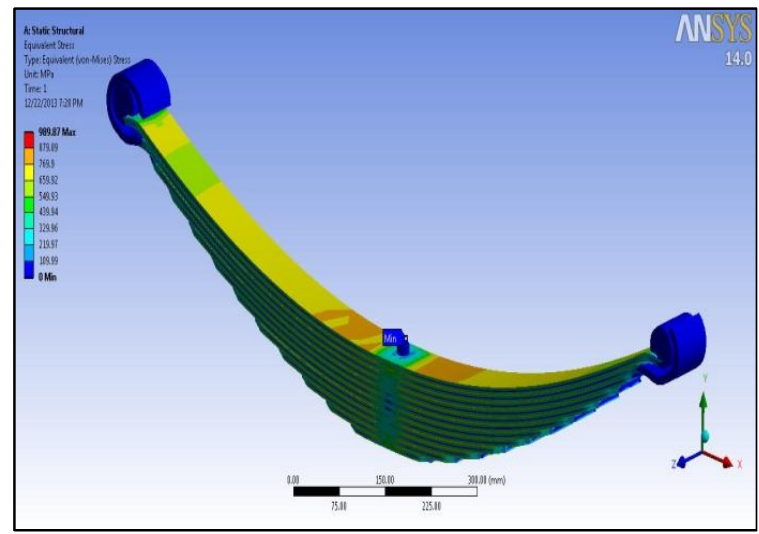

Fig. 9. Bending stress at metal to metal load

Fig. 10 shows that the total deformation is $127.02 \mathrm{~mm}$, when the rubber touching load $(21645.7 \mathrm{~N})$ is applied on the leaf springs. It is observed from the deformation contour that the maximum deformation occurs at the eye ends and minimum deformation occurs at the seat length region of the leaf springs. The figure 11 shows that the maximum stress induced is $765 \mathrm{MPa}$ in the leaf springs under the rubber touching load. It is also seen that eye end region corresponds to the minimum stress and seat length region corresponds to maximum stress in the leaf spring under this load.

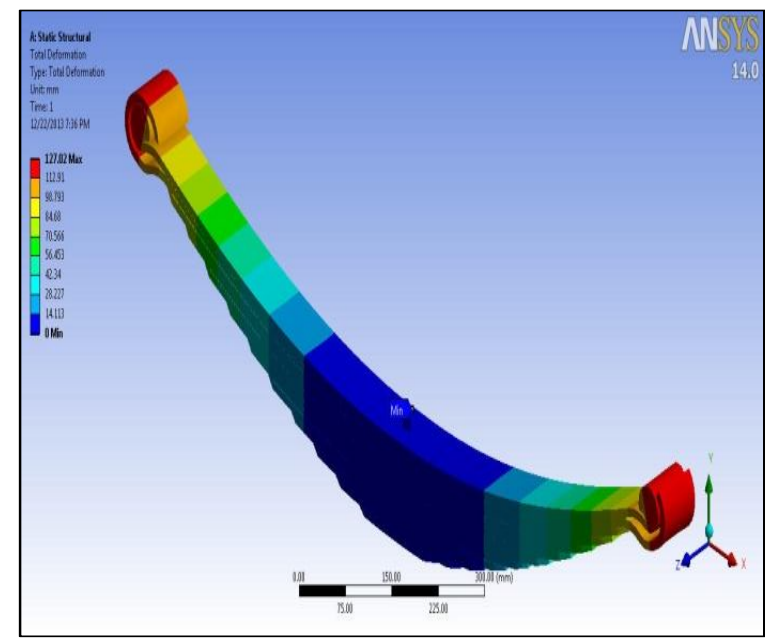

Fig. 10. Total deformation at rubber touching

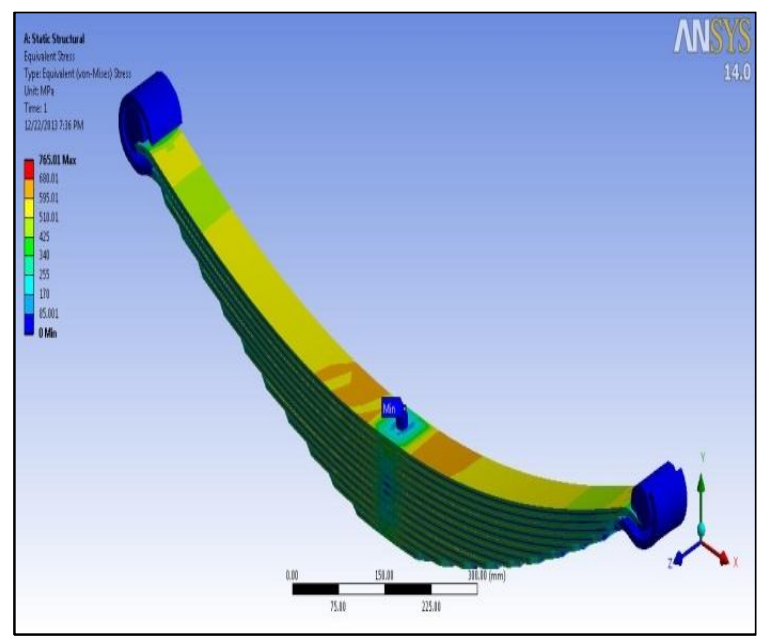

Fig. 11. Bending stress at rubber touching load load 
With the same model, the total deformation and bending stress induced in the leaf springs are also predicted by using similar loading conditions and under the application of flat load (15754N). Fig. 12 shows the deformation contours under the flat load. The maximum deformation observed is 92.45 $\mathrm{mm}$ in the eye region of the leaf spring and minimum deformation is observed in the seat length region of the leaf springs. Fig. 13 shows the bending stress contour under the flat load condition. The maximum stress observed in the leaf springs is $556.83 \mathrm{MPa}$ in the seat length region of the leaf springs.

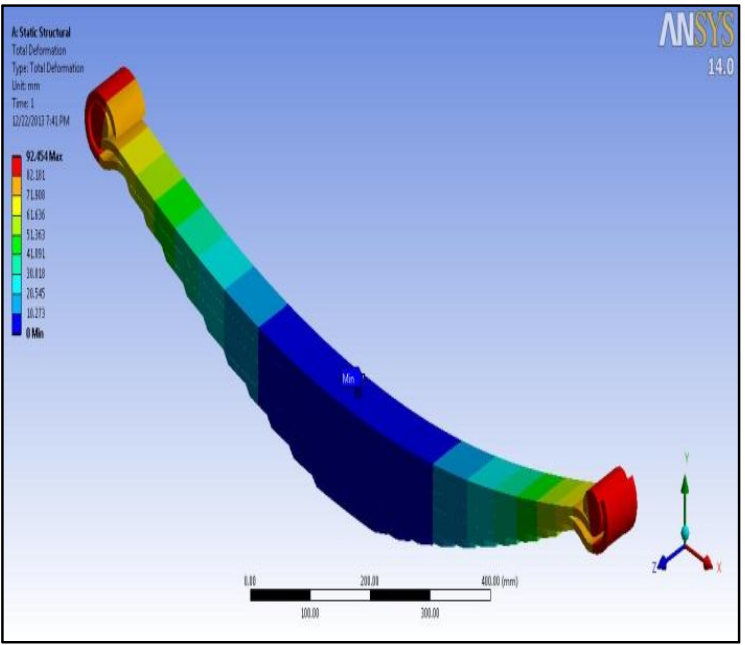

Fig. 12. Total deformation at flat load

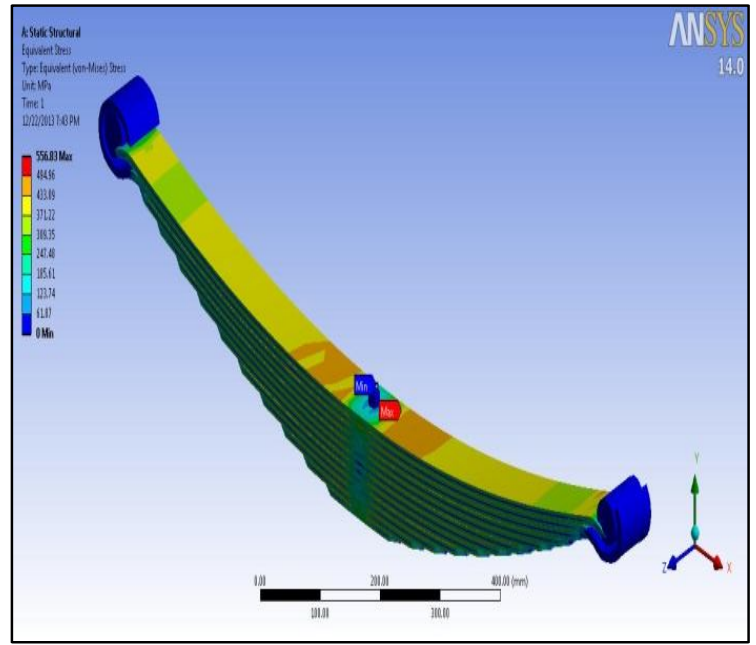

Fig. 13. Bending stress at flat load

The design load of $12959 \mathrm{~N}$ is applied on the leaf springs and the deformation contours and bending stress contours are shown in Figs. 14 and 15, respectively. It is observed from the deformation contour that the maximum deformation is $76.05 \mathrm{~mm}$, which occurs in the eye end region of the leaf springs. The minimum deformation occurs at the seat length region of the leaf springs. The maximum deformation is indicated by red colour in the deformation contour. The stress contours reveal that the maximum stress induced in the leaf springs is $458 \mathrm{MPa}$ in the seat length region of the leaf springs.

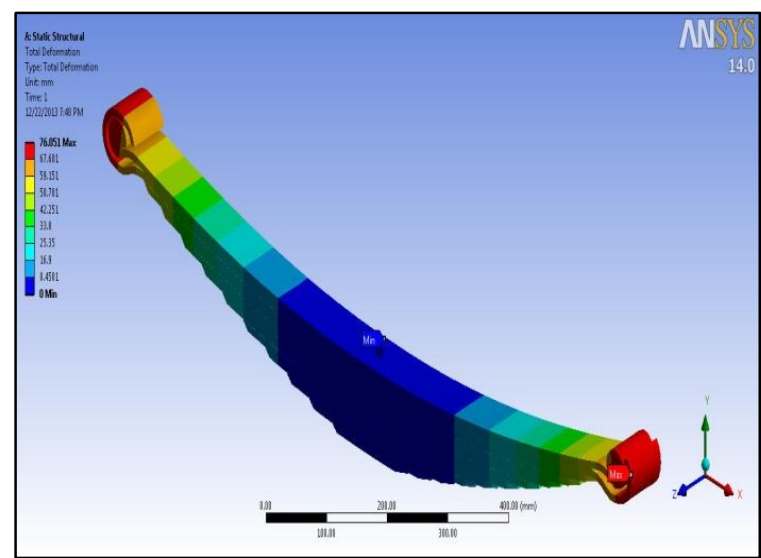

Fig. 14. Total deformation at design load

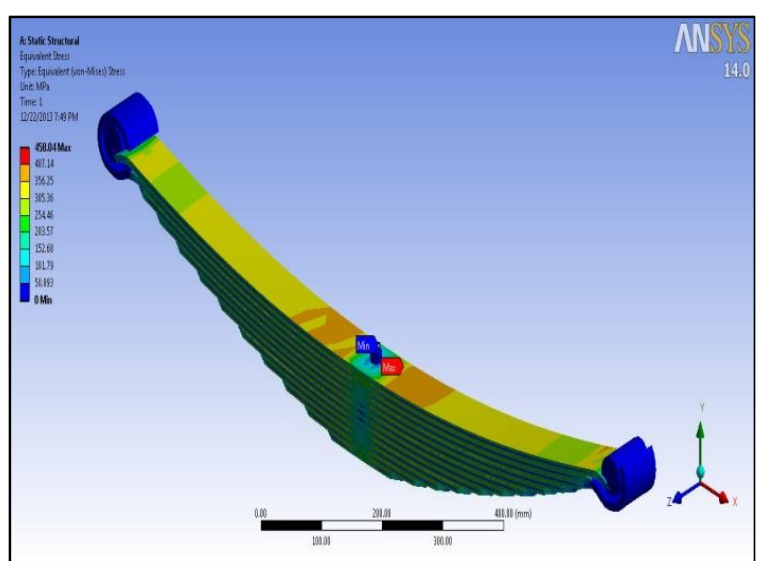

Fig. 15. Bending stress at design load

The deflection and stress results obtained from the specified loads have recorded in a tabular format. The CAE results for deflection and bending stress are shown in Table 4. 
Table 4. CAE results for load, deflection and bending stresses

\begin{tabular}{lllll}
\hline Spring No & Load type & Load $(\mathrm{N})$ & Deflection $(\mathrm{mm})$ & Stress(MPa) \\
\hline 1 & Unladen load & 7661 & 44.9 & 270.74 \\
2 & Design/Rated load & 12959 & 76.05 & 458 \\
3 & Flat load & 15754 & 92.45 & 556.83 \\
4 & Rubber touching load & 21645.7 & 127.02 & 765 \\
5 & Metal to Metal contact & 28010 & 164.36 & 989.89 \\
\hline
\end{tabular}

\section{Analytical approach for static analysis of leaf springs}

The term symmetrical leaf springs are used for the leaf springs in which the length of the front cantilever and rear cantilever is equal. The ratio of the cantilever length is called as cantilever ratio (Spring Design Manual 1990). For this leaf spring the cantilever ratio is one so it is called as symmetrical leaf spring. The steps involved in calculating the design parameters of the symmetrical leaf springs are as follows:

\subsection{Determination of Total Moment of Inertia of the section required for given rate}

$$
\sum I=\frac{k * L^{3}}{32 * E * S F} \quad \sum I=\frac{159.11 * 1150^{3}}{32 * 200124 * 1.1}=34351.7 \mathrm{~mm}^{4}
$$

where, $k=$ load rate, $L=$ spring span, $E=$ Young's Modulus, $\mathrm{SF}=$ Stiffening factor

\subsection{Determination of maximum permissible thickness for the leaf section}

$$
P_{\max }=P_{\text {design }}+k * X_{c} \quad P_{\max }=12959+(159.11 * 94.6)=28010.8 \mathrm{~N}
$$

where, $P_{\text {design }}=$ Design load, $X_{\mathrm{c}}=$ ride clearance

$$
t_{\max }=\frac{8 * \sum I * S_{\max }}{L * P_{\max }} \quad t_{\max }=\frac{8 * 34351.7 * 98 * 9.81}{1150 * 28010.8}=8.20 \mathrm{~mm}
$$

\subsection{Approximate determination of number of leaves for the required load rate}

$$
\sum I_{1}=N_{1} * i_{1}
$$

where, $N_{1}=$ No. of leaves with thickness $t_{1}, i_{1}=$ Moment of inertia for section $t_{1}=8 \mathrm{~mm}$, width $b$ $=70 \mathrm{~mm}$,

$$
i_{1}=\frac{b_{1}{ }^{\prime} * t_{1}{ }^{3}}{12}+\frac{3.1428 * t_{1}{ }^{4}}{64}
$$

where, $\mathrm{b}_{1}^{\prime}=\mathrm{b}-\mathrm{t}_{1}=62 \mathrm{~mm}, N_{1}=11$

$$
i_{1}=\frac{62 * 8^{3}}{12}+\frac{3.1428 * 8^{4}}{64}=2846.5 m^{4} \quad \sum I_{1}=11 * 2846.13=31311 m^{4} \quad \sum I_{2}=N_{2} * i_{2}
$$

where, $N_{2}=$ No. of leaves with thickness $t_{2}, i_{2}=$ Moment of inertia for section $t_{2}=7 \mathrm{~mm}$ width $b=$ $70 \mathrm{~mm}$,

$$
i_{2}=\frac{b_{2}{ }^{\prime} * t_{2}{ }^{3}}{12}+\frac{3.1428 * t_{2}{ }^{4}}{64}
$$


where, $N_{2}=1, b_{2}^{\prime}=\mathrm{b}-\mathrm{t}_{2}=63 \mathrm{~mm}$

$$
\begin{array}{cc}
i_{2}=\frac{63 * 7^{3}}{12}+\frac{3.1428 * 7^{4}}{64}=1918.6 \mathrm{~mm}^{4} & \sum I_{2}=1 * 1918.6=1918.6 \mathrm{~mm}^{4} \\
\sum I_{\text {total }}=\sum I_{1}+\sum I_{2} & \sum I_{\text {total }}=31311+1918.6=33230 \mathrm{~mm}^{4}
\end{array}
$$

7.4 Determining modified load rate

$$
\begin{aligned}
& K_{\text {modified }}=\frac{\sum I_{\text {total }}}{\sum I} * k \\
& K_{\text {modified }}=\frac{33230 * 159.11}{34351}=153.11 \mathrm{~N} / \mathrm{mm}
\end{aligned}
$$

$\%$ variation of $k=3.271 \%$ (Hence acceptable)

7.5. Maximum stress induced by considering total length of the leaf spring

$$
S_{\max }=\frac{P_{\max } * L * t}{8 * \sum I_{\text {total }}} \quad S_{\max }=\frac{28010.8 * 1150 * 8}{8 * 33230}=969.34 \mathrm{MPa}
$$

7.6 Approximate determination of weight

$$
m=\frac{\left(N_{1} * f_{1}+N_{2} * f_{2}\right) * \frac{L}{2} * S F}{1000} \quad m=\frac{(11 * 4.6+1 * 4.1) \frac{1150}{2} * 1.1}{(1000)}=34.59 \mathrm{Kg}
$$

$\mathrm{f}_{1}$ and $\mathrm{f}_{2}$ (Approximate)

\subsection{Determination of deflection and bending stress}

In the analytical approach the deflection can be determined as force per unit load rate. For different values of the load i.e. unladen load, rated load, flat load, rubber touching load and metal to metal contact load the corresponding values of deflection can be achieved. The stresses induced at different loads can be determined by substituting the values of the load in the stress induced formula. The analytical results for load, deflection and bending stress are shown in Table 5.

Table 5. Analytical results for load, deflection and bending stress

\begin{tabular}{lllll}
\hline Spring No. & Load type & Load $(\mathrm{N})$ & Deflection $(\mathrm{mm})$ & Bending Stress(MPa) \\
\hline 1 & Unladen load & 7661 & 50.3 & 265.2 \\
2 & Design/Rated load & 12959 & 84.6 & 448.48 \\
3 & Flat load & 15754 & 102.8 & 545.21 \\
4 & Rubber touching load & 21645.7 & 141.37 & 749.10 \\
5 & Metal to Metal contact & 28010 & 182.9 & 969.25 \\
\hline
\end{tabular}

\section{Results and Discussion}

\subsection{Experimental load rate}

From the experimental results obtained by loading and unloading of the leaf springs for load rate determination, a load -deflection curve is drawn for loading, unloading and mean load as shown in Fig. 16. The mean value of load shows a linear relationship with deflection but for loading and unloading this relationship is not linear. As observed that the relationship between load-deflection is not linear during the loading and unloading of the springs; therefore the mean value of loading and unloading to achieve $10 \mathrm{~mm}$ deflection is taken to determine the exact load rate. 


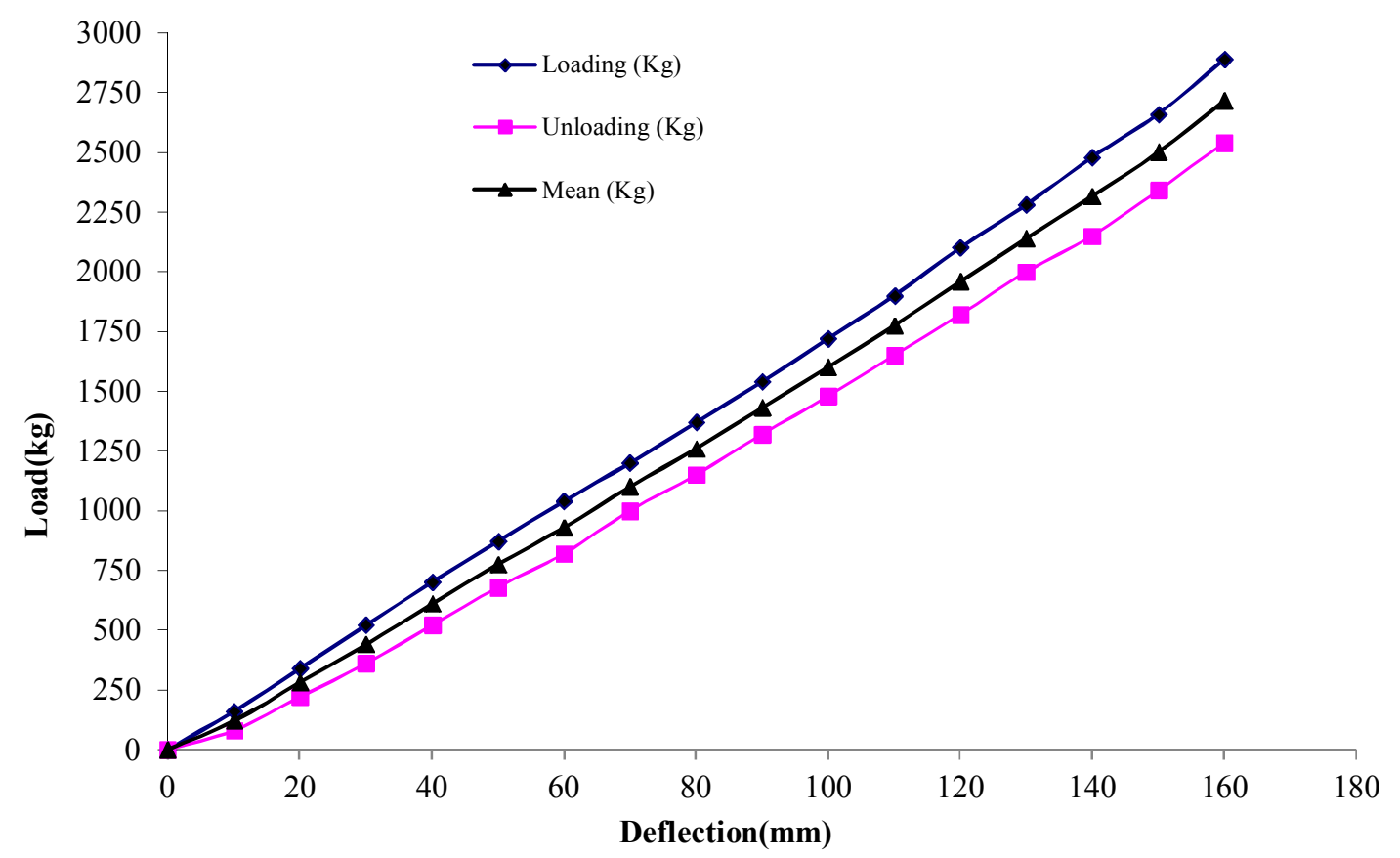

Fig. 16. Load rate testing in loading and unloading of leaf springs

\subsection{Experimental load deflection curve}

Fig. 17 shows an experimental load deflection curve, obtained by testing the leaf springs on a full scale leaf spring testing machines. The deflection observed under the application of the specified load is plotted. It is observed from this plot that there exist a liner relationship between the load and deflection.

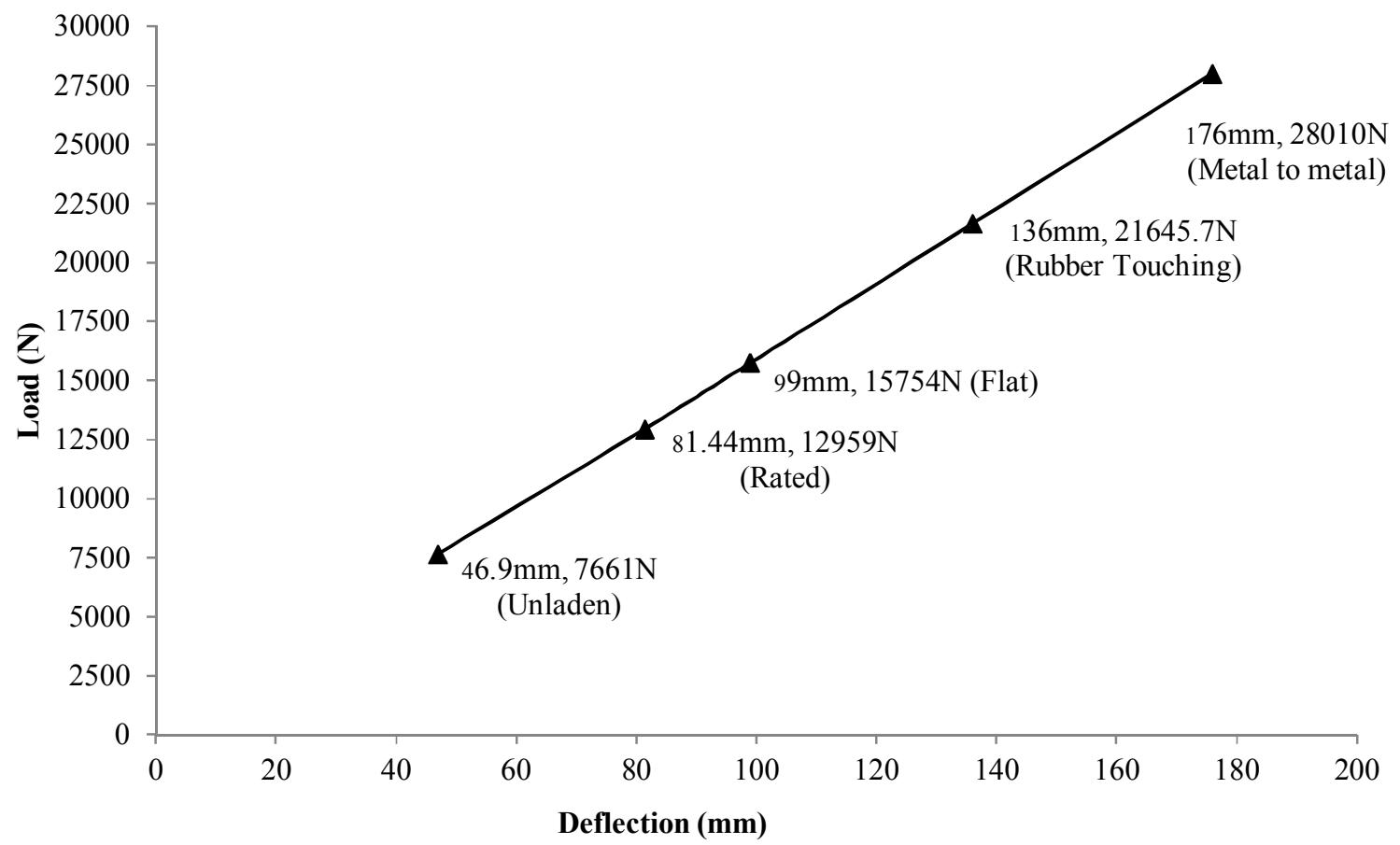

Fig. 17. Experimental load deflection curve 


\subsection{CAE load deflection curve}

Fig. 18 shows an analytical load deflection curve. The deflection observed under the application of the specified load is plotted. It is observed from this plot that there exist a liner relationship between the analytical load and deflection.

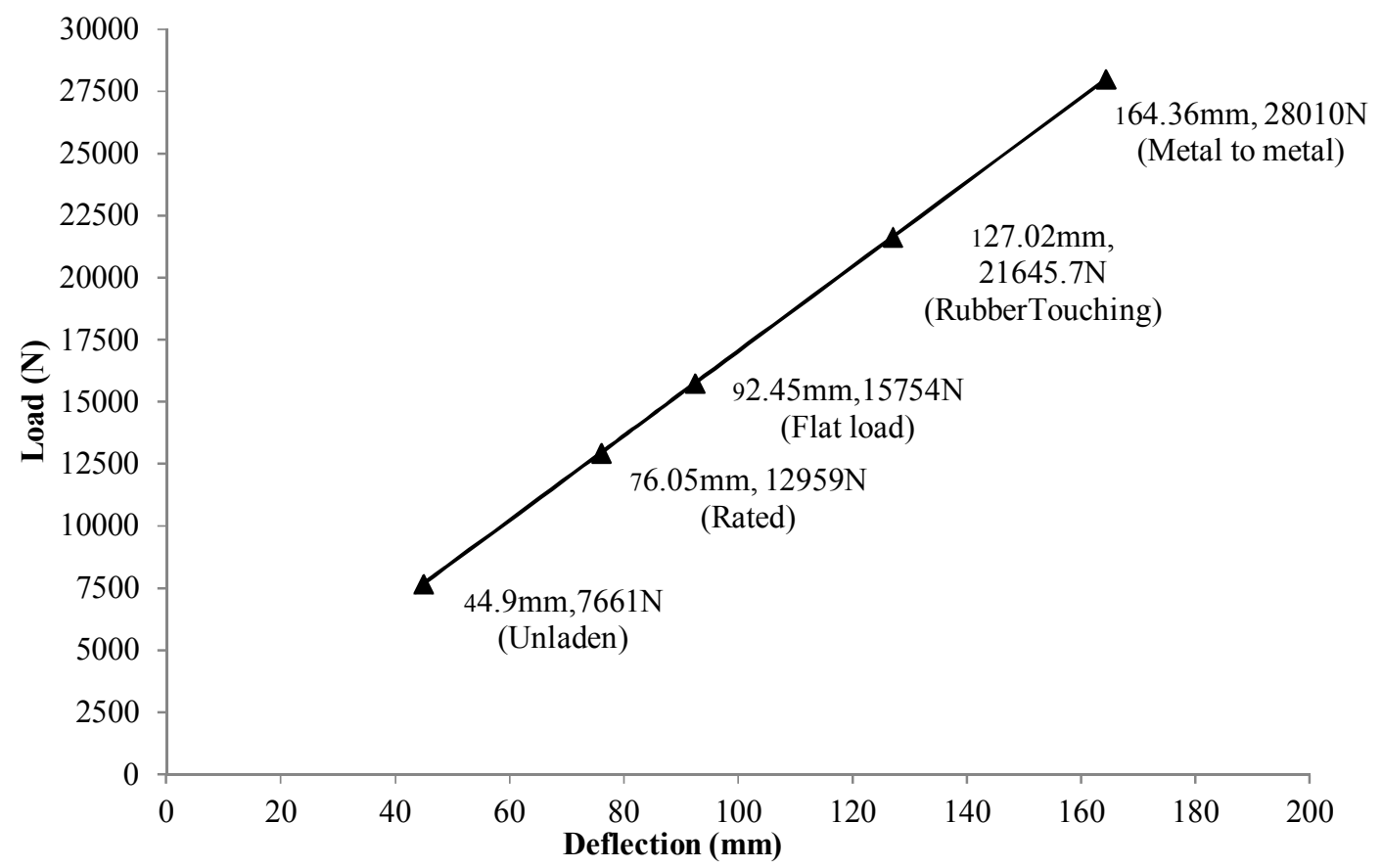

Fig. 18. CAE load- deflection curve

\subsection{Comparison of Experimental and Analytical results with CAE results}

To validate the analysis, the CAE results have been compared with the experimental results and analytical results. As the experiments are done on a full scale leaf spring testing machine under the specified loads, therefore the CAE analysis has been carried out for the same loads. The analytical method for determination of deformation and stress is also described. The maximum stress induced in the leaf springs is found to be $941 \mathrm{MPa}, 989.89 \mathrm{MPa}$ and $969.25 \mathrm{MPa}$ using experimental, CAE and analytical approach respectively. The stress is found to be well below the yield stress which is 1081.2 $\mathrm{MPa}$. The total deformation comparison for experimental, CAE and analytical approach also validates the CAE analysis of the leaf springs. The results of the comparison have been depicted in the tabular form in Table 6.

Table 6. Comparison of experimental, CAE and analytical results

\begin{tabular}{|c|c|c|c|c|c|c|c|c|c|c|c|}
\hline \multirow{2}{*}{ Load type } & \multirow{2}{*}{ Load(N) } & \multicolumn{2}{|c|}{$\begin{array}{l}\text { Experimental } \\
\text { results }\end{array}$} & \multicolumn{2}{|c|}{ CAE results } & \multicolumn{2}{|c|}{ Analytical results } & \multicolumn{2}{|c|}{$\begin{array}{l}\% \text { variation between } \\
\text { CAE \& Experimental } \\
\text { results }\end{array}$} & \multicolumn{2}{|c|}{$\begin{array}{l}\% \text { variation between } \\
\text { CAE \& Analytical } \\
\text { results }\end{array}$} \\
\hline & & $\begin{array}{l}\text { Deflection } \\
(\mathrm{mm})\end{array}$ & $\begin{array}{l}\text { Stress } \\
(\mathrm{MPa})\end{array}$ & $\begin{array}{l}\text { Deflection } \\
(\mathrm{mm})\end{array}$ & $\begin{array}{l}\text { Stress } \\
(\mathrm{MPa})\end{array}$ & $\begin{array}{l}\text { Deflection } \\
(\mathrm{mm})\end{array}$ & $\begin{array}{l}\text { Stress } \\
(\mathrm{MPa})\end{array}$ & Deflection & Stress & Deflection & Stress \\
\hline Unladen load & 7661 & 46.9 & 262 & 44.9 & 270.74 & 50.3 & 265.13 & 4.3 & 3.3 & 10.7 & 2.1 \\
\hline $\begin{array}{l}\text { Design/Rated } \\
\text { load }\end{array}$ & 12959 & 81.44 & 446 & 76.05 & 458 & 84.6 & 448.48 & 6.6 & 2.7 & 10.1 & 2.1 \\
\hline Flat load & 15754 & 99 & 540 & 92.45 & 556.83 & 102.8 & 545.21 & 6.6 & 3.1 & 10.1 & 2.1 \\
\hline $\begin{array}{l}\text { Rubber } \\
\text { touching load }\end{array}$ & 21645.7 & 136. & 743 & 127.02 & 765 & 141.37 & 749.10 & 6.6 & 3.0 & 10.1 & 2.1 \\
\hline $\begin{array}{l}\text { Metal to Metal } \\
\text { contact load }\end{array}$ & 28010 & 176 & 941 & 164.36 & 989.89 & 182.9 & 969.25 & 6.6 & 5.2 & 10.1 & 2.1 \\
\hline
\end{tabular}


From the Table 6 it is observed that for the same unladen static load conditions, deflection in experimental, CAE and analytical results are $46.9 \mathrm{~mm}, 44.9 \mathrm{~mm}$ and $50.3 \mathrm{~mm}$, respectively. The deformation observed in CAE results varies in the range of $4.3 \%$ to $10.7 \%$. The bending stress for experimental; CAE and analytical results are $262 \mathrm{MPa}, 270.74 \mathrm{MPa}$ and $265.13 \mathrm{MPa}$, respectively. The variation of bending stress observed in CAE results from experimental and analytical results lies in the range of $2.1 \%$ to $3.3 \%$. From the Table 6 it is also observed that, for the same design load condition, the deflection found in experimental, CAE and analytical results are $81.44 \mathrm{~mm}, 76.05 \mathrm{~mm}$ and $84.6 \mathrm{~mm}$, respectively. The variation in CAE results from experimental and analytical is $6.6 \%$ and $10.1 \%$, respectively. The bending stress under the design load for experimental, CAE and analytical results are $446 \mathrm{MPa}, 458 \mathrm{MPa}$ and $448 \mathrm{MPa}$, respectively. The variation in bending stress observed in the CAE results lies in the range of $2.1 \%$ to $2.7 \%$. The variation in deformation for CAE approach in the range of $6.6 \%$ to $10.1 \%$ and for stress it varies in the range of $2.1 \%$ to $3.1 \%$ under the flat load application on the leaf springs has been observed in Table 6. Similarly,under the application of rubber touching load on the leaf spring the variation in deformation is in the range of $6.6 \%$ to $10.1 \%$ for CAE approach, when compared with experimental and analytical approach under same load. The stress induced in the leaf springs varies in between $2.1 \%$ to $3.0 \%$ under same load.

For the maximum load condition the static deflection is $176 \mathrm{~mm}, 164.36 \mathrm{~mm}$ and $182.9 \mathrm{~mm}$ for experimental, CAE and analytical results. It has observed that when CAE results are compared with experimental and analytical methods, the variation in the deformation varies in between $6.6 \%$ to $10.1 \%$, respectively. The stress variation lies in the range of $2.1 \%$ to $5.2 \%$. It has also been observed that the maximum stress induced in the assembly in all the approaches is well below the yield stress of the material. It has been observed that the CAE results obtained by using SOLID 187 mesh elements and CONTA172 and TARGE170 (No separation and sliding) contact elements provides the results closer to the experimental and analytical methods.

8.5 Weight comparison by experimental, analytical and CAE approach

The weight of the leaf springs is dependent upon the leaf grades used to achieve the required load rate .The total weight of the leaf springs has been determined by using CAE and analytical method. The results obtained from CAE and analytical methods have been compared with the exact weight of the leaf springs used in the LCV. The weight calculated in the analytical method is just the approximate value, but in actual practise the exact weight of the leaf springs is more than the calculated value. The exact weight of the leaf spring is calculated after the eye diameter and leaf end constructions have been established. The total weight of the leaf springs in CAE approach is $37.9 \mathrm{Kg}$ whereas the exact weight of the leaf springs is $38.5 \mathrm{Kg}$. This variation is very small i.e. $1.5 \%$ because the actual mechanical properties have been used in the material used for CAD model. The results of the weight comparison have been depicted in the tabular form in Table 7.

Table 7. Comparison of exact, CAE and analytical weight of the leaf springs

\begin{tabular}{llll}
\hline Parameter & Exact weight & CAE approach & Analytical approach \\
\hline Weight & $38.5 \mathrm{~kg}$ & $37.9 \mathrm{~kg}$ & $35.02 \mathrm{~kg}$ \\
\hline
\end{tabular}

\section{Conclusions}

The static structural CAE analysis of a LCV leaf spring has been performed using ANSYS to predict the total deformation and stress induced in the leaf springs. The same LCV model has also been tested experimentally for deflection and stress in a full scale leaf spring testing machine. The load rate of the leaf spring has been determined experimentally. An analytical method for static analysis has also been described. The results from different approaches have been compared and discussed. The following conclusions are made from the results: 
1. The experiments show that the relationship between load and deflection is not linear, during loading and unloading of the leaf springs.

2. When the leaf springs is fully loaded under metal to metal contact load, a variation of $6.6 \%$ to $10.1 \%(\max )$ in deflection has been observed among the experimental, analytical and CAE results. The bending stress for fully loaded springs is found to be on higher side in CAE analysis. This may be attributed to the fact that individual leaf cambers are ignored in CAE analysis.

3. CONTA174, TARGE170 (contact elements) and SOLID187 3D (mesh element) are suggested for $\mathrm{CAE}$ analysis as the results obtained using these elements are closer to experimental results.

4. The CAE approach provides the approximate weight of the leaf springs within $1.5 \%$ variation of the exact weight, if the actual material properties are applied in the material used for CAD modelling and analysis.

5. The variation among CAE, experimental and analytical results for deflection and bending stress for various loading conditions are in the range of $4.3-10.7 \%(\max )$ and $2.1-5.2 \%(\max )$ respectively. Therefore CAE results can be considered by the leaf springs industry as CAE analysis can save a lot of time.

\section{Acknowledgement}

We would like to acknowledge Mr. P S Chawla and the leaf springs testing division of Friends Auto (India) Ltd, whose unconditional support have made this project successful.

\section{References}

Aggarwal, M. L., Khan, R. A., \& Agrawal, V. P. (2006 a). Optimization of micro welds in leaf springs used in automotive vehicles. Indian Journal of Engineering and Materials Sciences, 13(3), 217-220.

Aggarwal, M. L., Agrawal, V. P., \& Khan, R. A. (2006 b). A stress approach model for predictions of fatigue life by shot peening of EN45A spring steel. International journal of fatigue, 28(12), 1845 1853.

Arora, V., Aggarwal, M. L., \& Bhushan, G. (2011). A comparative study of CAE and experimental results of leaf springs in automotive vehicles. International journal of engineering science and technology, 3(9), 6856-6866.

Chantranuwathana, S., Kadekheaw P., Preedanood, P., Wichienprakarn,P, Kruo-ongarjnukool,P (2009) 'Experimental Verification of Leaf Spring Model by Using a Leaf Spring Test Rig',23rd conference of Mechanical Engineering Network of Thailand.

Fuentes, J. J., Aguilar, H. J., Rodríguez, J. A., \& Herrera, E. J. (2009). Premature fracture in automobile leaf springs. Engineering Failure Analysis, 16(2), 648-655.

Junior, G. S., Voorwald, H. J. C., Vieira, L. F. S., Cioffi, M. O. H., \& Bonora, R. G. (2010). Evaluation of WC-10Ni thermal spray coating with shot peening on the fatigue strength of AISI 4340 steel. Procedia Engineering, 2(1), 649-656.

Kumar, M. S., \& Vijayarangan, S. (2007). Analytical and experimental studies on fatigue life prediction of steel and composite multi-leaf spring for light passenger vehicles using life data analysis. Materials science, 13(2), 141-146.

Patunkar, M. M., \& Dolas, D. R. (2011). Modelling and Analysis of Composite leaf spring under the static load condition by using FEA. International Journal of Mechanical \& Industrial Engineering, 1(1-2011), 1-4.

SAE Spring Committee. (1990). Spring Design Manual. HS-744, AE-11, Society of Automotive Engineers.

Torabi, A., \& Aliha, M. (2013). Determination of permissible defect size for solid axles loaded under fully-reversed rotating bending. Engineering Solid Mechanics, 1(1), 27-36. 